\title{
LANGUAGE AND HUMAN NATURE: KURT GOLDSTEIN'S NEUROLINGUISTIC FOUNDATION OF A HOLISTIC PHILOSOPHY
}

\author{
DAVID LUDWIG
}

\begin{abstract}
Holism in interwar Germany provides an excellent example for social and political influences on scientific developments. Deeply impressed by the ubiquitous invocation of a cultural crisis, biologists, physicians, and psychologists presented holistic accounts as an alternative to the "mechanistic worldview" of the nineteenth century. Although the ideological background of these accounts is often blatantly obvious, many holistic scientists did not content themselves with a general opposition to a mechanistic worldview but aimed at a rational foundation of their holistic projects. This article will discuss the work of Kurt Goldstein, who is known for both his groundbreaking contributions to neuropsychology and his holistic philosophy of human nature. By focusing on Goldstein's neurolinguistic research, I want to reconstruct the empirical foundations of his holistic program without ignoring its cultural background. In this sense, Goldstein's work provides a case study for the formation of a scientific theory through the complex interplay between specific empirical evidences and the general cultural developments of the Weimar Republic. (C) 2012 Wiley Periodicals, Inc.
\end{abstract}

Holism in interwar Germany is often perceived as an irrationalist and antimodernist movement (Cooper, 1996, p. 102f; Popper, 1971, p. 63; Royce \& Mos, 1981, p. 13). Disorientated and troubled by the explanatory success of nineteenth-century science, the rapid industrialization of the German society, and a lost war of unknown proportions, Weimar era scholars turned to the ideal of wholeness as an alternative foundation of science and culture in general. The holistic idea that the whole is more than the sum of its parts served as a background argument against everything that seemed wrong with modern culture: a reductionist approach to human nature, an individualist society, and the loss of an aesthetic and religious world view.

Although the neuropsychologist Kurt Goldstein (1878-1965) is certainly one of the most influential figures of interwar holism, his approach does not fit the description of holism as an antimodernist irrationalism. According to Goldstein, holism has to be understood as a consequence of and not in opposition to modern science. In his neuropsychological research, Goldstein tried to show that linguistic abilities cannot be located in circumscribed areas of the brain, but can only be understood if the whole organism is taken into account. This neurolinguistic approach was meant to provide the empirical foundation of a holistic picture of human nature: the human mind is not decomposable into small mechanisms and "human behavior is intelligible only as viewed in connection with the organism as a whole" (Goldstein, 1938-1939/1951, p. 150).

In 1995, Oliver Sacks described Goldstein as "one of the most important [ ... ] and now most forgotten figures in the history of neurology" (Sacks, 1995, p. 7). Although Goldstein became highly influential in early postwar America, he was also quickly forgotten after his death in 1965 when a new generation of neurologists rejected holism as a philosophical

DAVID LUDWIG is a research fellow at the Helmholtz Centre for Kulturtechnik at the Humboldt University Berlin. His main interests lie in the history and philosophy of the life and mind sciences of the late 19th and early 20th centuries. 
obstacle to empirical research. Jürgen Tesak and Chris Code agree that Sacks' "assessment is not really too absurd, since, for instance, among the 3,000 references in a comprehensive survey of neurolinguistics [...] Goldstein does not get a single mention" (Tesak \& Code, 2008, p.137). However, in the last 15 years there has been a resurging interest in Goldstein (see, e.g., Danzer, 2005; Harrington, 1996; Kreft, 2005; Noppeney, 2000), which is closely connected to a generally increased attention toward holism and Gestalt theory.

Most importantly, Anne Harrington has described Goldstein as a member of the highly diverse holistic movement of the Weimar Republic. In her book Reenchanted Science, Harrington points out that holists of the Weimar Republic shared the conviction that modern science had become threat to a meaningful understanding of life. As Max Weber put it in his famous diagnosis of a disenchanted modernity: "where rational empirical knowledge has consistently carried through the disenchantment of the world and its transformation into a causal mechanism, there emerges a tension with the claims of ethical postulates - that the world, for religion, is ultimately willed and ordained by God and is therefore, in whatever way oriented, an ethically meaningful cosmos" (Weber, 2004, p. 238).

While many proponents of the holistic movement reacted to this perceived threat with a hostile attitude toward modern science, Goldstein warned about the tendency "towards the irrational and the mystical, fed by an enormous dissatisfaction and doubt regarding the possibility of a rational ordering of life" (Goldstein, 1931, p. 1). Given that authors such as Houston S. Chamberlain utilized this dissatisfaction to present a racist and "Germanic" alternative to modern society (Chamberlain, 1899), Goldstein argued emphatically that the problem was not modern science but the misunderstanding of it. According to Goldstein, holism was not an alternative to a scientific attitude but the consequence of a well-understood scientific perspective.

Goldstein's vision of a rational holism has much in common with the theoretical framework of the Berlin School of Gestalt Psychology. Max Wertheimer's use of the holistic Gestalt concept in an experimental and empirical setting also challenged the stereotypical dichotomy between a holistic antimodernism and a mechanistic science (see Ash, 1995, p. 3). Although Goldstein agreed with the Gestalt psychologists on the general vision of a rational holism, he also pointed out differences and insisted on the intellectual independence of his approach (Goldstein, 1938/1995, p. 285).

Goldstein and the Gestalt psychologists developed their approaches in the same cultural context; however, Goldstein took his neurological work to be an independent foundation of a holistic philosophy. This article will focus on Goldstein's neurolinguistic research in order to reconstruct his arguments for a holistic approach to human nature. The section Language and the Question of Localization will provide an overview of the neurolinguistic debate about localizationism and holism in late nineteenth and early twentieth century. In the last third of the nineteenth century, neurologists tried to locate linguistic abilities in circumscribed areas of the brain and offered detailed brain maps, which were supposed to explain the different aphasic symptoms. By the beginning of the twentieth century, a holistic counter movement rejected these attempts as empirically unjustified. The section Kurt Goldstein's "Paradoxical Position" describes Goldstein as a rather odd member of this holistic movement who accepted many localizationist claims about correlations between aphasic symptoms and circumscribed brain lesions. I will argue (see sections The Paradox Resolved and Empirical Evidence for the Holistic Program) that Goldstein's holistic and localizationist statements do not contradict each other but lead to a complex neurolinguistic model of the realization of linguistic abilities in the brain. The section Rational Arguments and Cultural Influences will describe Goldstein's general holistic program and discuss the relationship between Goldstein's research program and the broader cultural developments of the Weimar Republic. 


\section{LANGUAGE AND THE QUESTION OF LOCALIZATION}

In the beginning of the nineteenth century, Franz Joseph Gall's phrenology offered the first systematic attempt to locate cognitive functions in specific areas of the brain (Young, 1990, p. 11). According to Gall, personality traits can be detected by examining the cranium, because the cranium is formed by the shape of the brain. A surfeit or deficiency of a part of the brain will cause a detectable anomaly of the cranium and deliver the necessary data to determine personality traits by measuring the form of the skull. Although Gall's proposal was met with great public interest, the majority of scientists soon rejected his claims. According to Gall's critics, phrenology was nothing but a public spectacle and did not offer any evidence for correlations between personality traits and the form of the skull (Hagner, 1997, pp. 111-129).

The rise of phrenology made the localization of cognitive functions in the brain an interesting research question, but also left scientists with a fundamental methodological problem: there was no reliable data available to decide how cognitive functions are realized in the human brain. Additionally, Pierre Flourens physiological animal experiments seemed to suggest that cognitive functions are not located in circumscribed areas of the brain, but that every part of the brain is equally important for cognitive functions (see Tesak, 2001, pp. 56-60 for localizationist approaches before Broca). The situation began to change in the 1860s when the French physician and anthropologist Paul Broca presented his case studies of brain-damaged aphasic patients (Schiller, 1992). Broca argued that patients with an impaired speech production showed brain lesions in the third left frontal convolution, inferring that this brain area might be the seat of the lost linguistic knowledge. Although Broca's case studies were by no means revolutionary (Breidbach, 1996, p. 127; Tesak, 2001, p. 63ff), they set the stage for a new kind of localizationist research paradigm: correlations between clinical symptoms and brain lesions were now supposed to provide evidence for the location of underlying cognitive functions in the brain. If the damage of a circumscribed brain area caused a specific cognitive impairment, the corresponding brain area was assumed to be the seat of the damaged cognitive function.

This research program is most clearly formulated in Carl Wernicke's (1874) essay Der aphasische Symptomenkomplex. Eine psychologische Studie auf anatomischer Basis ("The aphasic symptom complex: A psychological study on a neurological basis"). Wernicke presented his aphasiological research as a contribution to the more general project of the localization of cognitive functions in the brain, but he also made clear that this project was different from Gall's phrenology. First, Wernicke used a different kind of data: instead of craniometry, neurological observations about brain-damaged patients were supposed to deliver the evidence. Secondly, Wernicke presented a different theory of how cognitive functions are realized in the brain. While phrenologists had tried to locate complex personality traits such as generosity, devotedness, or child's love in the brain, Wernicke claimed that only the "most basic mental functions can refer to specific locations of the cortex" (Wernicke, 1874, p. 4) Complex cognitive functions, such as language, are not located in circumscribed areas of the brain, but they are composed of more basic cognitive functions, which have specific locations.

The cortex is a mosaic of these simple elements, which are characterized by their connections to the periphery of the body. Everything that goes beyond these simple functions, the combination of simple impressions to a concept, thought, consciousness, is an achievement of the countless nerve fibers, which connect the different parts of the cortex. (Wernicke, 1874, p. 4)

In the case of language, Wernicke assumed two basic functions of major importance. The Bewegungsbilder (movement images) provide the necessary motor knowledge for speech and 


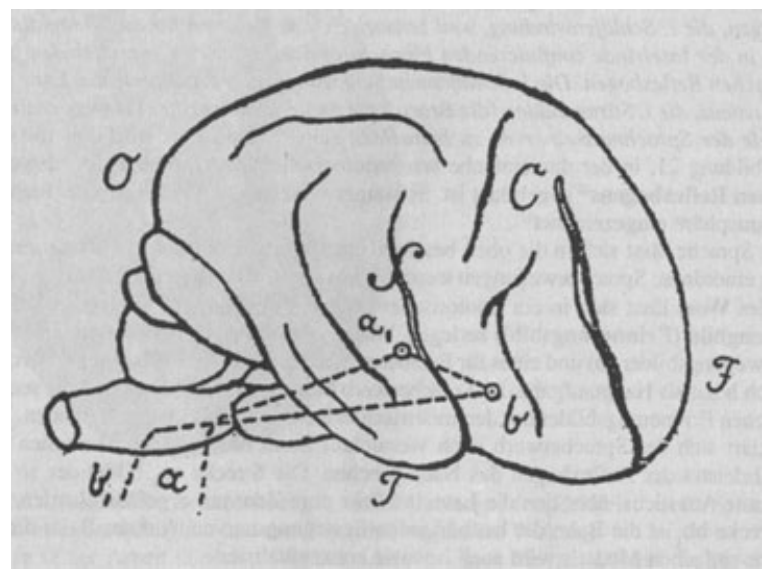

FIGURE 1 .

Wernicke's theory of aphasia. $\mathrm{a}_{1}$ is the seat of the sensory knowledge, and $\mathrm{b}$ the seat of motor knowledge. $\mathrm{aa}_{1}$ is the input path from the sensory organs to the sensory area, $b_{1} b$ is the output path from motor area to the motor organs, and $\mathrm{a}_{1} \mathrm{~b}$ connects the sensory and motor area. This model is supposed to allow the calculation of the variety of aphasic symptoms. (Wernicke, 1874).

are located in the third left frontal convolution. The Klangbilder (sound images) provide the necessary sensory knowledge to understand speech and are located in the posterior section of the superior temporal convolution. Aphasic symptoms can be caused by the destruction of these brain areas or the connections between them (see Figure 1).

Wernicke's essay became the founding document of a new neurological paradigm that tried to locate linguistic abilities in the brain. Neurological approaches of the end of the nineteenth century differed in many details but shared the basic idea that linguistic knowledge can be decomposed in numerous basic language functions, which can be located in specific brain areas (e.g., Lichtheim, 1885).

By the beginning of the twentieth century, the overwhelming influence of the localizationist tradition became contested by a new generation of neurologists. Criticism erupted all over Europe, most prominently represented by Pierre Marie in France, Henry Head in England, Christian von Monakow in Switzerland, and Kurt Goldstein in Germany (Tesak, 2001; Tesak $\&$ Code, 2008). Head dubbed the classical tradition "diagram makers" and accused them of deducing "the clinical manifestations from hypothetical lesions" instead of real cases (Head, 1926, p. 63). According to Head, the classical localizationists were so preoccupied with their elegant diagrams that they did not even bother with the complex reality of clinical research, which could never be grasped in simple diagrams.

The new holists did not only criticize the dubious empirical foundations of the classical diagrams. They also argued that the shortcomings of the diagrams were the result of a flawed theory of how linguistic abilities are realized in the brain. Contrary to the idea of a decomposable cognition, holists argued that aphasic symptoms had to be understood at least partly as the result of general disorders. Head claimed that linguistic performances were based on the fundamental ability to form symbols (Hudson, 1994, pp. 281-288); Marie argued that aphasia was caused by a general impairment of intelligence (Lebrun, 1994, pp. 219-230); and Goldstein saw the "abstract attitude" in the center of linguistic abilities (see section Rational Arguments and Cultural Influences). Despite the differences of these concepts, they all shared the idea that linguistic performances are based on general abilities, which cannot be located in specific brain areas. 
The aphasiological debate about localizationism and holism might appear to be a rather obscure controversy in a quite new research field plagued by many uncertainties. However, the holistic rebellion in neurology was closely connected to a general discontent with mechanistic explanation (Harrington, 1996; Lawrence \& Weisz, 1998; Ringer, 1969). The intellectual establishment, especially in Germany, revolted against "mechanistic science" and argued that it made humans blind and purposeless machines. If modern science reduced the human soul to an assembly of neural mechanisms and turned nature into a physical system governed by invariable laws, then the most important cultural values seemed at stake.

The consequence was ubiquitous talk of a crisis of science and the denunciation of the mechanistic worldview of the nineteenth century. Although there was a widespread agreement that modern science was in the state of a crisis, the proposals for an alternative differed widely as scholars such as Ludwik Fleck, Edmund Husserl, Jakob von Uexküll, and Max Wertheimer illustrate (see, e.g., Harrington, 1996; Rheinberger, 2007). Holism emerged from this debate as a vague concept that included a disparate family of approaches, which promised to encounter the shortcomings of mechanistic science by looking at the irreducible whole. For the following discussion of Goldstein's work, it is crucial to bear both aspects of the holism concept in mind: on the one hand, holism was the name of a more or less specific stance in a specialized neurological debate. On the other hand, it was a vague concept, which was used in countless variations to counter the consequences of mechanistic science.

Goldstein's attempt to combine specific empirical research with a general holistic attitude resembles the better-known case of the Berlin School of Gestalt psychology and Goldstein is often treated as a more neurologically oriented proponent of Gestalt theory. This is understandable given that Goldstein was not only theoretically but also personally close to the Gestalt psychologists. Most famously, Goldstein collaborated with the Gestalt psychologist Adhémar Gelb in the treatment of the patient "Schn" who was presented as being unable to organize visual presentations into coherent "wholes" due to neurological impairment (Goldenberg, 2003; Goldstein \& Gelb, 1918; Marotra \& Behrmann, 2004). However, Goldstein insisted that his holistic approach went further than the Gestalt concept, as it did not only treat perception but also the perceiving organism as an irreducible whole: "Our basic view agrees in many respects with Gestalt psychology. [... ] Yet my guiding principle has been a different one, inasmuch as the 'whole,' the 'Gestalt' has always meant to me the whole organism and not the phenomena in one field, or merely the 'introspective experiences"” (Goldstein, 1938/1995, p. 285).

\section{KURT GOLDSTEIN's “PARADOXICAL POSITION”}

Without any doubt, Kurt Goldstein's work is of outstanding importance for the holistic movement in the first half of the twentieth century. This applies both to neurological holism in the narrow sense as well as to the broader cultural debates. In the field of neurology, Goldstein started with traditional localizationist assumptions (Goldstein, 1906), but by the 1920s he turned to a holist conception of neurology claiming that the attempt to localize linguistic abilities in the brain had been a fatal mistake. In his 1927 handbook chapter on the Lokalisation in der Großhirnrinde (Localization in the Cerebral Cortex), Goldstein offered a detailed account of the localizationists' shortcomings and his alternative holistic proposal.

But Goldstein did not content himself with the criticism of localizationist approaches to language. On the contrary, he was quite clear that his neurological arguments had to be understood as a case against a much broader scientific and cultural misunderstanding of human 
nature. He even went so far as to suggested that the rejection of the localizationist program was a direct consequence of general criticism toward the mechanistic stance:

The times, in which the isolated analysis and view held almost absolute dominance in science, humanities and non-scientific understanding [ ... ] have passed. This also applies to the ideas of the classical school in aphasiology, which was based on these once vivid but now overcome ideas. (Goldstein, 1927b, p. 230)

Goldstein's holistic arguments and proclamations show clearly that his scientific approach has to be understood in context of the general discontent with "mechanistic science" in the Weimar Republic. Like every scientist in interwar Germany, Goldstein was well aware of the ubiquitous evocation of a "crisis of science." Among others, Fritz Ringer has pointed out that the "theory of cultural decadence was [...] very much in fashion. Almost habitually, men continued to lament a loss of soul and a conviction, the growth of relativism and determinism, the isolation of the creative individual. [...] The theme of a crisis was now a ritual and an obsession.” (Ringer, 1969, p. 385). Goldstein's philosophical background also ensured that he was familiar with the common holistic proposals to overcome the crisis and there is no doubt that he understood his own research as a part of this larger cultural movement. It might, therefore, appear that Goldstein's theory of language is just an application of the general holistic stance to his own area of research.

This interpretation is not entirely wrong, but a closer look into Goldstein's work reveals it as an oversimplification. First of all, Goldstein's approach to neurology was not meant to be a special science application of a general holistic stance. Rather, his theory of language was supposed to offer the very foundations of a holistic approach to human nature. For Goldstein and many of his contemporaries, the localizationist school in neurology appeared at the very core of the flawed mechanistic understanding of human nature. The neurolinguistic attempt of the classical school to identify basic linguistic abilities and to localize them in circumscribed areas of the brain was seen as the forefront of the general program to decompose the mind into numerous cognitive mechanisms and to identify them with specific neural structures. As a consequence, any successful holistic program had to offer an alternative account of neurolinguistics and neurology in general.

There is also another and even more striking reason why Goldstein's theory of language should not solely be understood as an application of a general holistic stance to a special scientific subject. Despite his own holistic statements and proclamations, Goldstein's neurological writings do not turn out as unambiguously holistic as one would expect. Especially illuminating is his 1927 Lokalisation in der Großhirnrinde that starts with the expected general attack on the localizationist program and the presentation of an alternative holistic account:

For the unprejudiced observer a living organism is not a composition of ears, eyes, brain, legs, etc., but is an organism with ears, eyes, brain, legs, etc. The psychological human is not a composition of his thoughts, speech, actions, feelings [...] but he is a thinking, speaking, feeling, visually experiencing human. (Goldstein, 1927a, p. 630)

Despite these kinds of remarks, Goldstein accepts Paul Broca's "flawless establishment of the dependency of the impairment of articulated speech from a lesion in the third left frontal convolution" (Goldstein, 1927a, p. 620). Furthermore, the entire second half of the article is devoted to an almost classical account of different forms of aphasia 
and Goldstein's basic classification of aphasic symptoms barely differs from localizationist presentations:

1. First, Goldstein discusses peripheral forms of aphasia, which include Wortstummheit ("word dumbness" or "motor aphasia") and Worttaubheit ("word deafness" or "sensory aphasia"). Word dumbness and word deafness mirror Broca's and Wernicke's aphasia and Goldstein does not deny the traditional claim that they are caused by circumscribed lesioned areas in the brain.

2. Second, Goldstein turns to the Zentrale Aphasie (central aphasia), which is characterized by Goldstein as a dedifferentiation of inner speech. Often, language production and understanding are to a large extent intact while disturbances such as repetition, paraphasia, and syntactic mistakes occur. Goldstein states that central aphasia is nothing but his preferred name for conduction aphasia, which had already been described by Wernicke in his landmark essay on the "aphasic symptom complex." Goldstein disagrees with Wernicke's term conduction aphasia "because we are not dealing with a defect of conduction $[\ldots]$ but with dedifferentiation of a complex apparatus which I believed to be justified to 'localize' in the center of the speech area" (Goldstein, 1927a, pp. 759-795).

3. Finally, Goldstein describes the Amnestische Aphasie (amnesic aphasia) as possessing the dominant symptom of a severe problem in recalling words or names. Goldstein argues that amnesic aphasia is caused by an impairment of the ability to form abstract concepts. This explanation is quite unique and will be discussed in section Empirical Evidence for the Holistic Program.

Goldstein's basic classification of aphasic symptom complexes is not revolutionary, but mirrors the traditional localizationist accounts in many ways. Of course, his classification differed in some ways from Wernicke's traditional proposal. But this was far from surprising, since even the localizationist camp did not agree on one kind of classification and Wernicke's (1874) diagram was considered outdated in many ways. Given these observations, Goldstein's approach does not seem to be a holistic rejection of localizationism. On the contrary, Goldstein offers a more or less traditional classification of aphasic symptoms and even accepts that different symptom complexes can be correlated with brain lesions at different locations of the brain.

One might object that Goldstein differs from classical localizationism because he constantly stresses the problems of every attempt to classify aphasic symptom complexes. Individual cases are always more complex than general terms suggest and a lot of information is lost by classifying them as motor aphasia, sensory aphasia, and so on: "Schematic distinctions $[\ldots]$ produce a misconception of the facts because they neglect a finer analysis of symptoms" (Goldstein, 1948, p. viii). Also, it is not easy to find neural correlates of symptom complexes - case studies show too many different lesions and psychological symptoms to allow simple localizations. Although Goldstein may place an extraordinary emphasis on these problems, he does not say anything remarkably controversial. Even his most dedicated localizationist contemporaries were well aware of these problems and had no intentions to deny them.

Goldstein's quite traditional discussion of aphasic symptom complexes despite his general holistic statements can leave the reader somewhat puzzled. Norman Geschwind, the founding figure of modern aphasiology, has called Goldstein's stance toward holism and localizationism a "paradoxical position" and has even asked the question "Who is the real Kurt Goldstein?" 
(Geschwind, 1962/1997, p. 69). Indeed, Goldstein's ambiguous statements are puzzling. Is Goldstein contradicting himself? Is he proposing a moderate view between holism and localizationism? In the following, I want to argue that Goldstein is neither contradicting himself nor proposing an intermediate position. Rather, the apparent contradiction between Goldstein's holism and localization can be resolved by a more careful discussion of his methodological program.

\section{THE PARADOX RESOLVED}

An especially instructive example for Goldstein's apparently paradoxical stance is his discussion of motor aphasia. The main symptom of this kind of aphasia is the difficulty or even inability to produce (spoken or written) language, while word comprehension is generally preserved. In a discussion of motor aphasia, Goldstein notes that "the anatomical localization of this type of aphasia correspondents to the classic area of Broca, though not in the limited sense of the foot of the third frontal convolution, as it is usually assumed" (Goldstein, 1948, p. 199). For Goldstein, there is no reasonable doubt about the importance of the third frontal convolution for motor aphasia. He even explicitly rejects Niessl von Meyendorf's alternative hypothesis that motor aphasia is caused by damage of the operculum of the precentral convolution (Von Meyendorf, 1911). The real research questions are whether the neural correlate of motor aphasia has to be extended beyond the traditional assumed structure of the third frontal convolution and how additional symptoms are related to lesions of neighboring regions.

Goldstein stresses that these questions remain largely open: "There are numerous anatomic components involved in the structure of motor speech, and in any given case, we have great difficulty in attempting to determine the significance of the various defects for the impairment of motor speech" (Goldstein, 1948, p. 205f). This call for caution, however, was not disputed by Goldstein's contemporaries and cannot be seen as a serious argument against localization of motor speech in the brain.

At a first glance, Goldstein's theory of motor aphasia seems to be barely different from classical localizationism, but a closer look reveals that a crucial qualification is necessary. While it is true that Goldstein accepts correlations between aphasic symptoms and circumscribed brain areas, the main point of his holism is not what neural correlates can be found, but how these correlates have to be understood. According to Goldstein, the fatal flaw of the localizationist tradition is an unjustified interpretation of the neurolinguistic data:

Already Broca made the important and fatal step when he went from the initial localization of symptoms to the localization of functions [by] claiming the foot of the third frontal convolution as the seat of the ability to articulate speech. (Goldstein, 1927a, p. 619)

To understand Goldstein's holism, it is important to differentiate between two aspects of the localization problem. On the one hand, localization in a weak sense can mean the correlation of symptoms and brain lesions. Goldstein does not reject this kind of weak localizationism, although he often points out that the classical tradition had been too optimistic in its attempts to identify circumscribed neural structures. On the other hand, the classical tradition understands localization in a much stronger sense. Strong localizationism starts with correlations between aphasic symptoms and brain lesions, but goes a step further by taking the neural correlates as evidence for the seat of linguistic abilities in the brain. In the case of 
motor aphasia, classical localizationists argue that the correlations show that the knowledge necessary for language production is actually located in this part of the brain. In this sense, Wernicke assumed that the third frontal convolution is the seat of the Bewegungsvorstellungen (movement images), which allow expression of thoughts in speech. It is exactly this strong interpretation of localizationism that is rejected by Goldstein. Empirical observations of neurolinguistic correlations are innocent as long as they are not misunderstood in the sense of the strong localizationist program. Goldstein stresses this point by arguing that "one can deny circumscribed localization and nevertheless ascribe to the lesion of a circumscribed part of the brain a particular significance for a definite disturbance" (Goldstein, 1948, p. 25).

The differentiation between "weak localizationism" and "strong localizationism" therefore allows the apparent paradox in Goldstein's work to be dissolved. Indeed, Goldstein is a holist and a localizationist, but this only sounds paradoxical if one does not discern different meanings of the word "localization." As soon as one understands that Goldstein accepts localization in the sense of correlation and rejects it in the stronger sense, the paradox disappears.

The differentiation between a weak and a strong version of localizationism might show that Goldstein is not contradicting himself, but it does not follow that Goldstein's version of holism is actually convincing. Correlations do not appear miraculously and we can expect an explanation as to why lesions of specific brain areas correlate with certain aphasic symptoms. The strong localizationist program offers an elegant explanation: if the necessary linguistic abilities are actually located in specific brain areas, it is obvious that lesions of these areas will lead to certain aphasic symptoms, while holistic proclamations about the importance of the whole organism are no explanation for neurolinguistic correlations. On the contrary, from a holistic point of view one might expect that no part of the brain plays a crucial role in creating linguistic symptoms. Goldstein obviously has to explain why the strong localizationist program is not the best or even the only explanation for the neurolinguistic data and how the holistic stance is a viable option in the light of neural correlates of aphasic symptoms.

This problem leads to the core of Goldstein's holistic theory of aphasia. Its main task is to offer an alternative and empirically more adequate explanation of neural correlates. Goldstein's first step is a simple argument to show that the strong program of localization is not a necessary consequence of correlations between aphasic symptoms and specific brain areas. According to Goldstein there are at least two possible explanations for the loss of a linguistic ability due to brain damage. The classical localizationists give the first explanation: the linguistic ability is lost because it is located in the damaged brain area. But there is another explanation that has been ignored by the classical tradition: the linguistic ability could also be lost because the damaged brain area is a crucial element of a larger structure that realizes linguistic abilities (Goldstein, 1927a, p. 638f). In this sense, it might be possible that a linguistic ability is realized in the whole organism while some parts of the organism play a more important role than others. The more important the parts are, the more severe the cognitive damage caused by a lesion will be.

A helpful illustration of this holistic argument can be provided by Goldstein's use of the Gestalt concept (Goldstein, 1938-1939/1951, p. 23). The Gestalt of a picture can be easily damaged or lost by the damage of a small part of the picture: if we have a picture of a house and destroy a small part of it, we might not be able to recognize it as a house anymore. But this does not mean that the Gestalt of the house can be located in the damaged part of the picture. The Gestalt is rather realized by the whole picture and the damaged part was a crucial element of this larger structure. The same is true in the case of aphasia: a linguistic ability can easily be damaged or even lost by a lesion of a small part of the brain. Again, however, this does not mean that the linguistic ability can be located in the damaged part of the brain. 


\section{EMPIRICAl EVIDENCE FOR THE Holistic PROGRAM}

The argument of the last section was meant to establish the possibility of an alternative explanation of correlations between aphasic symptoms and brain lesions, but it did not show that the holistic explanation actually fits better the available neurolinguistic data than the localizationist model. One of Goldstein's most important tasks, therefore, is to find empirical evidence for the holistic program and against the localizationist interpretation of aphasia.

According to Goldstein the central shortcoming of the localizationist interpretation is its simplistic description of symptoms, which obscured the real diversity of individual cases (Goldstein, 1939/2000, p. 35). Most patients do not fit neatly in textbook categories as motor aphasia or sensory aphasia but show a unique pattern of negative and positive symptoms. To understand these patterns, one has to give up the idea that symptoms are caused only by the direct damage of a linguistic ability and has to look at the real diversity of causes. Goldstein proposes a classification of four different kinds of causes for symptoms (Goldstein, 1927a, p. 633; Goldstein, 1948, p. 3).

1. The damaged area of the brain might be crucial for a linguistic ability so that the lesion has a direct effect on it. This is the classical case of a symptom being directly caused by a lesion.

2. A symptom can also be caused by the isolation of an undamaged area from the damaged one. The performance of an area depends on its neural connections with other areas. If an undamaged area becomes isolated from other areas, its performance will be altered. Goldstein cites exaggerated and abnormal reflexes in the field of speech logorrhea as an example.

3. Often, an undamaged area starts to work differently because it is affected by the changed processing of the damaged area. According to Goldstein, this becomes evident when the neurosurgical removal of a damaged area has a positive effect on the symptoms of a patient.

4. Finally, symptoms might be caused by the catastrophic reaction of the organism. The term "catastrophic reaction" was coined by Goldstein to refer to a state of confusion and anxiety which is caused by the patient's sudden inability to perform certain tasks. Typical symptoms of the catastrophic reaction include frustration, aggression, and the tendency to avoid challenging situations.

The unique patterns of individual cases of aphasia are produced by the entanglement of all four kinds of causes. In Goldstein's own words:

The survey regarding the factors determining the configuration of symptoms are only partly the direct results of the damage. It has further become evident that, to a greater or lesser degree, the symptoms are an expression of the organism's struggle with the defect in its attempt to adjust itself in spite of some interference by the defect. (Goldstein, 1948, p. 19)

The consequence of this multicausal explanation is "that every individual's speechperformance is understandable only from the aspect of its relation to the function of the total organism in its endeavor to realize itself as much as possible in the given situation" (Goldstein, 1948, p. 21). Neurolinguistic symptoms are the result of an interaction between damaged brain areas, the undamaged part of the brain, and the rest of the organism. This makes the localizationists "fallacy of isolation" (Goldstein, 1948, p. 20) obvious as the 
classical tradition assumes that the damaged linguistic ability can be located in the damaged part of the brain alone.

Additionally, Goldstein argues that only this holistic model of symptom causation can explain observations about restitution and retaining of lost linguistic capacities. If one thinks of the brain as a simple machine, restitution seems hardly possible. If a part of the machine is broken, then it is broken and does not fix itself. Indeed, "therapeutical nihilism (as it was called by its critics) had, by the fin-de-siècle, become endemic throughout German-speaking medicine" (Harrington, 1998, p. 27). This attitude changed when World War I produced large numbers of young, brain injured patients with circumscribed lesions from gunshots. Most patients were able to recover at least partly from their symptoms and Goldstein stressed that clinical therapy and training are important factors in the process of restitution (see Kreft, 1929, pp. 262-266).

But how is the process of restitution to be understood from a neurological point of view? If cognitive functions were located in circumscribed brain areas, one would not expect damaged functions to recover from brain lesions. If the whole neural basis of a cognitive function is gone, little hope is left. Goldstein's holistic model allows another prediction: if aphasic symptoms are the product of a complex interaction of different parts of the brain, one would expect the organism to try to find ways to solve problems without the damaged area. This is exactly what is observed in clinical practice, the organism reacts to the damage in a way that allows restitution.

So far we have seen how Goldstein tried to support his holistic model with observations about the causation and restitution of aphasic symptoms. But there is also another line of argument that depends on Goldstein's famous concept of the "abstract attitude" (for a detailed discussion, see Noppeney, 2000, pp. 103-162). The abstract attitude is defined as the ability of a person to form abstract concepts in contrast with the concrete attitude in which a person is only aware of her immediate surroundings. As an illustration of the difference between the abstract and the concrete attitude, Goldstein often refers to the Holmgren test, which was initially developed for the diagnosis of color blindness (Goldstein \& Gelb, 1918). In the Holmgren test, a patient is asked to pick skeins of the same color from a heap. The abstract attitude allows the patient to form general color concepts and therefore manage the task. Patients with an impaired abstract attitude are not successful. They are driven by their immediate impressions and might start to sort the skeins by color and then switch to sorting them by brightness. They might only pick out the skeins, which have exactly the same color, or end up picking out skeins of very different colors.

Each of these aspects is so unstable and emerges so rapidly that we see the heap as fluctuating and at the same time experience a rivalry between the constantly moving congruencies. (Goldstein \& Scheerer, 1941, p. 59)

The example of the Holmgren test illustrates how the abstract attitude allows a person to structure her experience with the help of general concepts. Goldstein argues that the overwhelming importance of the abstract attitude makes it the basic element of complex linguistic abilities. He even extends this claim beyond the realm of language and states that the abstract attitude offers the foundations of the following potentials:

1. Assuming a mental set voluntarily, taking initiative, even beginning a performance on demand.

2. Shifting voluntarily from one aspect of a situation to another, making a choice. 
3. Keeping in mind simultaneously various aspects of a situation; reacting to two stimuli, which do not belong intrinsically together.

4. Grasping the essential of a given whole, breaking up a given whole into parts, isolating them voluntarily, and combining them to wholes.

5. Abstracting common properties, planning ahead intentionally, assuming an attitude toward the "mere possible," and thinking or performing symbolically

6. Detaching the ego from the outer world (Goldstein, 1948, p. 6).

The idea of one basic function of complex linguistic abilities or even cognition in general has been a focus of criticism of Goldstein from the beginning (Isserlin, 1929; Noppeney, 2000, p. 117). Much of this criticism might be justified but is not relevant for his argument in favor of neurolinguistic holism. To present the abstract attitude as evidence against classical localizationism, Goldstein does not have to show that the ability to form abstract concepts is the basic function of language or even cognition in general. He just has to show that it is too basic to be localized in one part of the brain.

According to Goldstein, not every form of aphasia is characterized by an impairment of the abstract attitude, "patients might be divided into two groups in which [the abstract attitude] is or is not impaired" (Goldstein, 1948, p. 5). Goldstein's most prominent example of an impaired abstract attitude is amnesic aphasia. Patients with amnesic aphasia usually have good speech comprehension, speak fluently and are able to repeat words. The main symptom is "the lack of sounds, adjectives, verbs and especially names for concrete objects in speech" (Goldstein, 1948, p. 246). Goldstein presents one case study of a 60-year-old German woman who suffered from an amnesic aphasia after "having been hit on the head." Her memory for previous events and intelligence were intact or at least almost intact and she spoke fluently with normal emphasis and rhythm. Her symptoms became most apparent when she had to name objects or pictures as the following transcript illustrates:

Objects shown
Uhr
Watch
Wozu ist es?
What is it for?
Picture shown
Kuh
Cow
Huhn
Hen

Answer

Ein Stückle, wo man sieht, ein schönes Stückle, hätt Ich nur so ein. A thing, where one sees a nice thing, if I just had one. Es ist jetzt halb fünf, schöns Stückle, Rundelle, eins, zwei, drei, vier, fünf. It is four-thirty now (correct), nice thing, Rundelle, one, two, three, four, five.

Answer

Wo man's Ding holt, wo man tut überfahren. Milch, wissen Sie wir hatten zehn Kühe. Where one gets the thing, where one is passing over (shows the udders and makes milking movement). Milk, you know we had ten cows. Wo man Eier bekommt, weisse Rundelle.

Where one gets eggs, white Rundelle. (Goldstein, 1948, p. 248)

The patient was obviously still able to recognize the presented objects and pictures but she was not able to name them anymore. Goldstein interprets this symptom as an impairment of the abstract attitude. The patient reported her immediate associations but did not use abstract and general concepts. This became especially clear when she used the correct word "cow" as a part of her recollection but not as general concept in the naming task.

From a neurological point of view, amnesic aphasia and the impaired abstract attitude differ from other forms of aphasia and symptoms because they cannot be correlated with damage in one specific brain area. This is not just because cases of pure amnesic aphasia are rare but because the "[a]bstract attitude is a very high mental function and thus probably 
related to complex anatomic structures which may be damaged early even in fine lesions" (Goldstein, 1948, p. 288). Not every part of the brain is equally important for the abstract attitude but there is not one central area in the brain either. Rather the symptom of an impaired abstract attitude "is to be found especially in cases of lesions of the frontal lobes, but it may also be observed to some extent in cases of lesions of other parts of the cortex (particularly in patients with lesions of the left hemisphere)" (Goldstein, 1948, p. 5). The case of the abstract attitude therefore illustrates another shortcoming of the strong localizationist program. Higher mental functions have no circumscribed neural correlates and hence cannot be located in one specific area of the brain.

\section{RATIONAL ARGUMENTS AND CULTURAL INFLUENCES}

In the previous two sections, I have argued that it is helpful to differentiate between two possible meanings of localization. Goldstein accepts weak localizationism in the sense of neural correlations of aphasic symptoms but he rejects the strong interpretation of linguistic abilities actually being located in circumscribed parts of the brain. He offers a wide array of arguments against the strong localizationist program and in favor of his holistic interpretation of neurolinguistic correlations: classical localizationism misses the diversity of causes for aphasic symptoms, it cannot explain observations about the recovery from aphasia, and it does not offer an account of higher mental functions involved in linguistic abilities. The result is a neurolinguistic holism that accepts data of neural correlates but still maintains that linguistic abilities have to be understood with respect to the whole organism.

On a more general level, Goldstein's holism was not just supposed to be a theory about linguistic abilities, but also to offer the foundations of a holistic understanding of human nature. Goldstein and many of his contemporaries perceived the localizationist program as a cornerstone of a mechanistic understanding of human nature: the localization of cognitive functions in specific brain areas leads to the decomposition of the human mind into countless mental mechanisms, which are identified with neural mechanisms. Contrary to this mechanistic "brick model" of human nature, the holistic approach was meant to offer the foundations of an alternative picture based on the idea that human behavior has to be understood in connection with the organism as a whole. This implied that isolated neural mechanisms or conditioned reflexes cannot explain human behavior, and that it is rather necessary to examine "the basis of the individual life history, which contains bodily processes, attitudes, and conscious events. All these events have to be considered in their configurational relation within the given individual according to the situation in which they originally took place, and they have to be evaluated according to their present significance for the individual's coming to terms with his environment" (Goldstein, 1938-1939/1951, p. 169f).

Goldstein joined the widespread denunciation of "mechanistic science" and the call a holistic reorientation. Contrary to large parts of the German holistic movement, however, he did not see the mechanistic picture of human nature as a necessary consequence of modern science. Rather, he saw it as a consequence of a wrong understanding of modern science. According to Goldstein, holists do not have to reject scientific research programs such as neurology and they do not have to fear their empirical results. They just have to understand them in the right way. Goldstein therefore tried to go beyond the popular dichotomy of disenchanting mechanistic science and reenchanting holistic irrationalism. For Goldstein this is a faulty alternative, because it is based on the assumption that the mechanistic understanding of human nature is implied in modern science. The alternative to mechanistic science is not irrationalism but a rational holism based on the results of modern neurology. 
Goldstein's understanding of holism as the result of a rational research program inevitably brings up the question of its relation to the cultural movements of interwar Germany. Indeed, I have reconstructed Goldstein's arguments in a way that makes holism a conclusion rather than a premise of his neurological work. However, it is equally correct to take the holistic rejection of a mechanistic stance as a fundamental premise of Goldstein's work. This is not only true with respect to his general motivation, but also affects how specific arguments are understood. For example, I have presented Goldstein's work with brain-injured soldiers as an empirical evidence for the holistic program: Goldstein was able to detect patterns of recovery from aphasia that did not seem explainable within the localizationist framework. Goldstein, therefore, concluded that his clinical observations required a different, holistic understanding of neurological symptoms. At the same time, Goldstein's holistic rejection of a mechanistic account was also a premise of his therapeutic approach, fostered by the whish to overcome "therapeutic nihilism" and to find a more optimistic approach to neurological disorders. Anne Harrington has argued that "Goldstein's desire to create an alternative to the 'therapeutic nihilism' of fin-de-siecle Central European medicine seems to have been a powerful (if generally unspoken) shaping force behind many of his later biological ideas. Indeed, it could be argued that the existential attitude and epistemology that evolved in the context of his developing science would become his answer to the implicit nihilism of modernism generally" (Harrington, 1991, p. 441).

There is no contradiction in taking holism as both a conclusion and a premise of Goldstein's research program. On the contrary, Goldstein's holistic neurology is such an interesting case study in the history of the human sciences precisely because it shows the complex interplay of specific empirical evidences and general cultural factors. As a member of the Weimar scientific community, Goldstein perceived the contemporary life and mind sciences as in the state of a great crisis and his work is shaped by conviction that a major reorientation is necessary. At the same time, Goldstein did not follow the irrationalist denunciation of modern science but understood himself a rational scientist in the search of the empirically most adequate theory. The dynamics of Goldstein's scientific development cannot be understood through the opposition of rational reconstruction and cultural history but requires recognizing both aspects as inextricably tangled.

\section{ACKNOWLEDGMENTS}

I would like to thank Veronika Lipphardt, William Lockhart, Tania Munz, Ian Nicholson, and the anonymous reviewers for their helpful comments and suggestions.

\section{REFERENCES}

Ash, M. (1995). Gestalt psychology in German culture, 1890-1967: Holism and the quest for objectivity. Cambridge, UK: Cambridge University Press.

Breidbach, O. (1996). Die Materialisierung des Ichs: zur Geschichte der Hirnforschung im 19. und 20. Jahrhundert. Frankfurt: Suhrkamp.

Chamberlain, H. S. (1899). Die Grundlagen des neunzehnten Jahrhunderts. Munich: Bruckmann.

Cooper, D. (1996). Verstehen, Holism and Fascism In O’Hear, Anthony. Verstehen and Humane Understanding. Cambridge: Cambridge University Press.

Danzer, G. (2005). Vom Konkreten zum Abstrakten im Leben und Werk Kurt Goldstein's (1878-1965). Frankfurt: Vas-Verlag für Akademische Schriften.

Geschwind, N. (1965). Disconnexion syndromes in animals and man. Brain, 88, 237-294.

Geschwind, N. (1997). The paradoxical position of Kurt Goldstein in the history of Aphasia. In O. Devinsky \& S. C. Schachter (Eds.), Norman Geschwind: Selected publications on language, epilepsy, and behavior. (p. 53) Dordrecht: Reidl. 
Geschwind, N., \& Kaplan, E. (1962). A human cerebral deconnection syndrome. Neurology, 12, 675-685.

Goldenberg, G. (2003). Goldstein and Gelb's case Sch: A classic case in neuropsychology? In C. Code, C. W. Wallesch, Y. Joanette, \& A. R. Lecours (Eds.), Classic cases in neuropsychology, Vol. II (pp. 281-300). New York: Psychology Press.

Goldstein, K. (1906). Ein Beitrag zur Lehre von der Aphasie. Journal für Psychologie und Neurologie, 7, $172-188$.

Goldstein, K. (1927a). Die Lokalisation in der Grosshirnrinde nach den Erfahrungen am kranken Menschen. Berlin: Julius Springer.

Goldstein, K. (1927b). Über Aphasie. Zürich: O. Füssli.

Goldstein, K. (1931). Das psychophysische problem in seiner Bedeutung für ärztliches Handeln. Therapie der Gegenwart, $72,1-11$.

Goldstein, K. (1938-1939/1951). Human nature in the light of psychopathology. Cambridge, MA: Harvard University Press.

Goldstein, K. (1938/1995). The organism: A holistic approach to biology derived from pathological data in man. New York: Zone Books.

Goldstein, K. (1948). Language and language disturbances aphasic symptom complexes and their significance for medicine and theory of language. New York: Grune \& Stratton.

Goldstein, K., \& Gelb, A. (1918). Psychologische Analysen hirnpathologischer Fälle. Zeitschrift fur die gesamte Neurologie und Psychatire, 41, 1-142.

Goldstein, K., \& Scheerer, M. (1941). Abstract and concrete behavior: An experimental study with special tests. The American Psychological Association, 53, 1-151.

Hagner, M. (1997). Homo cerebralis : der Wandel vom Seelenorgan zum Gehirn. Berlin: Berlin Verlag.

Harrington, A. (1991). Interwar "German" psychobiology: Between nationalism and the irrational. Science in Context, 4, 429-447.

Harrington, A. (1996). Reenchanted science: Holism in German culture from Wilhelm II to Hitler. Princeton, NJ: Princeton University Press.

Harrington, A. (1998). Kurt Goldstein's neurology of healing and wholeness: A Weimar story. In C. Lawrence \& G. Weisz (Eds.), Greater than the parts: Holism and biomedicine, 1920-1950 (pp. 25-45). Oxford: Oxford University Press.

Head, H. (1926). Aphasia and kindred disorder of speech. Cambridge: Cambridge University Press.

Hudson P. (1994). Henry Head. In P. Elling (Ed.), Reader in the history of Aphasia: From Franz Gall to Norman Geschwind. Amsterdam: John Benjamins.

Isserlin, M. (1929). Die pathologische Physiologie der Sprache. München: J.F. Bergmann.

Kreft, G. (1929). Deutsch-jüdische Geschichte und Hirnforschung: Ludwig Edingers Neurologisches Institut in Frankfurt am Main. Frankfurt am Main: Mabuse-Verlag.

Lawrence, C., \& Weisz, G. (1998). Greater than the parts. Oxford: Oxford University Press.

Lebrun, Y. (1994). Pierre Marie. In P. Elling (Ed.), Reader in the history of Aphasia: From Franz Gall to Norman Geschwind. Amsterdam: John Benjamins.

Lichtheim, L. (1885). Über Aphasie. Deutsches Archiv für klinische Medizin, 36, 204-268.

Marotta, J. J., \& Behrmann, M. (2004). Patient Schn: Has Goldstein and Gelb's case withstood the test of time? Neuropsychologia, 42, 633-638.

Noppeney, U. (2000). Abstrakte Haltung: Kurt Goldstein im Spannungsfeld von Neurologie, Psychologie, und Philosophie. Würzburg: Königshausen \& Neumann.

Popper, K. R. (1971). Das Elend des Historizismus. Tübingen: Mohr.

Rheinberger, H. J. (2007). Zur Historizität wissenschaftlichen Wissens: Ludwik Fleck, Edmund Husserl. In O. G. Oexle (Ed.), Krise des Historismus-Krise der Wirklichkeit, Wissenschaft, Kunst und Literatur. Göttingen: Vandenhoeck und Ruprecht.

Ringer, F. (1969). The decline of the German mandarins: The German academic community, 1890-1933. Middletown, CT: Wesleyan University Press.

Royce, J. R., \& Leendert, P. M. (1981). Humanistic psychology. New York: Plenum Press.

Sacks, O. (1995). Introduction. In K. Goldstein, The organism. New York: Zone Books.

Schiller, F. (1992). Paul Broca: Founder of French anthropology, explorer of the brain. Oxford: Oxford University Press.

Tesak, J. (2001). Geschichte der Aphasie. Idstein: Schulz-Kirchner.

Tesak, J, \& Chris, C. (2008). Milestones in the history of Aphasia: Theories and protagonists. New York: Psychology Press.

Von Meyendorf, N. (1911). Die aphasischen Symptome. Leipzig: Engelmann.

Weber, M., \& Whimster, S. (2004). The essential Weber: A reader. London: Routledge.

Wernicke, C. (1874). Der aphasische Symptomencomplex, eine psychologische Studie auf anatomischer Basis. Breslau: M. Cohn und Weigert.

Young, R. M. (1990). Mind, brain, and adaptation in the nineteenth century: Cerebral localization. Oxford: Oxford University Press. 